deviations were reported for continuous variables. Number and percentages were shown for categorical variables and chi-square test was utilised for comparison. T- test was used to compare patients between the groups.

Results: Total of 1362 patients with SLE fulfilling revised ACR criteria were included; $60.9 \%$ were Caucasian and 32.8\% African American. 596 had biopsyproven LN however 524 patients were excluded because they had proteinuria before or at cohort entry. Only first available BMI were analysed: $32.7 \%$ were obese $\left(B M I>30 \mathrm{~kg} / \mathrm{m}^{2}\right.$ ), $27.2 \%$ overweight (BMI: $\left.25-29.9 \mathrm{~kg} / \mathrm{m}^{2}\right), 37.5 \%$ normal (BMI: $18.5-24.9 \mathrm{~kg} / \mathrm{m}^{2}$ ) and $2.6 \%$ underweight $\left(\mathrm{BMl}<18.5 \mathrm{~kg} / \mathrm{m}^{2}\right) .39 .4 \%(537)$ patients were on steroids at first BMI measurement. Results are described in table 1. BMI measured as continuous $(p=0.51)$ and categorical variables (overweight $p=0.64$, obese $p=0.67$ ) were not associated with $L N$ after adjusting for age, sex and ethnicity. SLE patients with obesity were found to have lower disease activity (SLEDAI), proteinuria, dsDNA titers and higher complement levels.

Abstract AB0538 - Table 1. SLE Patients with vs without Lupus Nephritis $(P<0.05$ in bold $)$

\begin{tabular}{|c|c|c|c|}
\hline & $\begin{array}{l}\text { Lupus } \\
\text { Nephritis } \\
(\mathrm{n}=72) \\
\text { Mean (SD) } \\
\text { /N (\%) }\end{array}$ & $\begin{array}{c}\text { SLE without Lupus } \\
\text { Nephritis } \\
(\mathrm{n}=1290) \\
\text { Mean (SD) } \\
\text { /N (\%) }\end{array}$ & P Value \\
\hline Age when $\mathrm{BMI}$ are measured & $32.07(8.4)$ & $42.53(13.48)$ & $<0.0001$ \\
\hline Kidney Biopsy Age & $35.14(10.9)$ & - & \\
\hline $\begin{array}{l}\text { Ethnicity } \\
\text { Caucasian }\end{array}$ & $20(27.78 \%)$ & $811(62.87 \%)$ & $<0.0001$ \\
\hline Asian & $5(6.94 \%)$ & $36(2.79 \%)$ & \\
\hline African American & $42(58.33 \%)$ & $404(31.32 \%)$ & \\
\hline Others & $5(6.94 \%)$ & $39(3.02 \%)$ & \\
\hline Male & $6(8.33 \%)$ & $76(5.89 \%)$ & 0.4387 \\
\hline $\begin{array}{l}\text { Age when SLE was } \\
\text { diagnosed }\end{array}$ & $27.39(8.47)$ & $35.46(12.85)$ & $<0.0001$ \\
\hline BMI (continuous) & $26.93(6.72)$ & $28.02(7.32)$ & 0.1855 \\
\hline BMI (Categorical) & $32(44.44 \%)$ & $475(36.82 \%)$ & 0.6242 \\
\hline Underweight & & & \\
\hline Normal Weight & $2(2.78 \%)$ & $38(2.95 \%)$ & \\
\hline Overweight & $19(26.39 \%)$ & $372(28.84 \%)$ & \\
\hline Obesity & $19(26.39 \%)$ & 405 (31.4\%) & \\
\hline SLEDAI (continuous score) & $5.04(4.03)$ & $2.13(2.8)$ & $<0.0001$ \\
\hline $\operatorname{SLEDAI}(\geq 2)$ & $65(90.28 \%)$ & $690(53.61 \%)$ & $<0.0001$ \\
\hline Anti dsDNA $(\geq 10)$ & $40(59.7 \%)$ & 252 (20.31\%) & $<0.0001$ \\
\hline Low C3 $(<79)$ & $37(53.62 \%)$ & $178(14.19 \%)$ & $<0.0001$ \\
\hline Low C4 $(<12)$ & 27 (39.13\%) & $146(11.67 \%)$ & $<0.0001$ \\
\hline ESR $(>20)$ & $47(70.15 \%)$ & $576(47.56 \%)$ & 0.0004 \\
\hline
\end{tabular}

Conclusions: Obesity was not associated with the development of lupus nephritis. Obese patients with SLE had lower disease activity as measured by SLEDAI, dsDNA titers and complement levels.

Disclosure of Interest: None declared

DOI: 10.1136/annrheumdis-2018-eular.4524

\section{AB0539 CORRELATION BETWEEN MORPHOLOGICAL AND FUNCTIONAL MICROVASCULAR DAMAGE IN SYSTEMIC LUPUS ERYTHEMATOSUSPATIENTS}

A. Sulli ${ }^{1}$, B. Ruaro ${ }^{1}$, C. Pizzorni ${ }^{1}$, V. Smith ${ }^{2}$, S. Paolino ${ }^{1}$, M. Pendolino ${ }^{1}$, L. Verni ${ }^{1}$, M. Cutolo ${ }^{1}$. ${ }^{1}$ Research Laboratory and Academic Division of Clinical Rheumatology, Department of Internal Medicine, University of Genova, San Martino Polyclinic Hospital, Genoa, Italy, ${ }^{2}$ Department of Rheumatology, Ghent University Hospital, Department of Internal Medicine, Ghent University, Ghent, Belgium

Background: Numerous articles have investigated peripheral microcirculation in primary Raynaud's phenomenon (PRP). ${ }^{1-3}$ However, reports that analyse peripheral microcirculation in systemic lupus erythematosus (SLE) are scanty. ${ }^{45}$

Objectives: The aim of this study was to investigate possible correlations between morphological and functional aspects of microcirculation in different skin areas of the hands and face in SLE patients and to compare the results with PRP patients and healthy subjects (HS).

Methods: A total of 14 SLE patients without RP (ACR criteria) ${ }^{6}$ (mean age 53 \pm 14 SD years, mean disease duration $7 \pm 4$ years), 14 PRP patients (LeRoy and ACR/EULAR 2013 criteria) ${ }^{7} 8$ (mean age $53 \pm 17$ years, mean RP duration $6 \pm 5$ years) and $14 \mathrm{HS}$ (mean age $50 \pm 17$ years) were enrolled during the winter period. Nailfold videocapillaroscopy (NVC) and laser speckle contrast analysis (LASCA) were performed in the three groups of patients. The absolute nailfold capillary number $(\mathrm{CN})$ per linear millimetre at first distal row was assessed by NVC. Blood perfusion (BP) was detected by LASCA at the level of fingertips, periungual areas, dorsum and palm of both hands and face. The average BP was calculated as perfusion units (PU). ${ }^{2}$ Patients were not taking vasodilator drugs since at least one month. Statistical analysis was performed by non parametric tests.
Results: SLE patients showed a positive correlation between BP and nailfold CN in all areas of hands $(p<0.0001)$, but no statistically significant correlation was observed between BP and nailfold $C N$ at the level of face $(p=0.10)$. In both PRP and $\mathrm{HS}$ no statistically significant correlation was observed between BP and nailfold $C N$ in all examined areas $(p=0.70$ and $p=0.20$, respectively). SLE patients showed a statistically significant lower nailfold CN than both PRP and HS (median 9.1 vs 10.3 vs 11.0 , respectively, $p<0.0005$ ). Conversely, no statistically significant difference of nailfold CN was observed between PRP and HS. PRP patients showed a statistically significant lower BP than both SLE and HS at the level of fingertip (median 90, 114, $187 \mathrm{PU}$, respectively; $\mathrm{p}<0.0001$ ), periungual (median 74 100, $141 \mathrm{PU}$, respectively, $\mathrm{p}<0.0001$ ), dorsal (median 61, 72, $128 \mathrm{PU}$, respectively, $\mathrm{p}<0.0001$ ), and palm areas (median 76, 96, $124 \mathrm{PU}$, respectively, $\mathrm{p}<0.0001)$. Conversely, PRP, SLE and HS patients showed similar BP values at the level of face (median 141, 139, $137 \mathrm{PU}$, respectively, $\mathrm{p}=0.30$ ).

Conclusions: This study demonstrates a correlation between morphological and functional microvascular features in SLE patients. SLE patients without RP have a subclinical microangiopathy, showing lower nailfold $\mathrm{CN}$ and BP than HS. Conversely, PRP patients show only a functional dysfunction, having a lower peripheral skin BP than both SLE patients and HS. The clinical value of this new finding is undergoing further analysis.

\section{REFERENCES:}

[1] Cutolo M, et al. J Rheumatol 2010;37:1174-80.

[2] Ruaro B, et al. Ann Rheum Dis 2014;73:1181-5.

[3] Rosato E, et al. Rheumatology 2009;36:2257-63.

[4] Anania C, et al. Lupus 2012;21:815-20.

[5] de Leeuw K, et al. Lupus 2008;17:1010-1017.

[6] Petri M, et al. Arthritis Rheum. 2012;64:2677-86.

[7] van den Hoogen F, et al. Ann Rheum Dis 2013;72:1747-55.

[8] LeRoy EC, et al. Clin Ex Rheumatol 1992;10:485-8.

Disclosure of Interest: None declared

DOI: 10.1136/annrheumdis-2018-eular.4233

\section{AB0540 USEFULNESS OF CARDIAC SCREENING IN PATIENTS WITH SYSTEMIC LUPUS ERYTHEMATOSUS AND ANTI- RO POSITIVE ANTIBODIES}

A. Olivé $^{1}$, M. Martínez-Morillo ${ }^{1}$, R. Villuendas ${ }^{2}$, A. Teniente-Serra ${ }^{3}$, A. RiverosFrutos $^{1}$, S. Heredia ${ }^{1}$, Á. Prior-Español ${ }^{1}$, S. Holgado ${ }^{1}$, L. Mateo ${ }^{1}$, M. Aparicio ${ }^{1}$, L. Gifre ${ }^{1}$, G. Juncà ${ }^{2}$, E. Martínez-Cáceres ${ }^{3}$, A. Bayes-Genis ${ }^{2} .{ }^{1}$ Rheumatology; ${ }^{2}$ Cardiology; ${ }^{3}$ Immunology, Hospital Universitari Germans Trias i Pujol, Badalona, Spain, Badalona, Spain

Background: Cardiac block in neonatal lupus is associated with placental trans fer of anti-Ro antibodies. The effect of these antibodies on cardiac conduction disorders in adult patients is controversial. The association between anti-Ro antibodies and heart rhythm disorders have been described in isolated cases. However, there are just a few studies that analyse the relationship between autoimmune diseases and electrocardiographic disturbances.

Objectives: To determine if there are differences in cardiac conduction of SLE patients in presence of anti-Ro antibodies.

Methods: All patients included fulfilled the SLE criteria, SLICC 2012 and they were followed up in a single centre. The inclusion was consecutive and voluntary Patients who took drugs that altered the conduction (except antimalarial drugs), and those who had heart or thyroid disease were discarded. All patients were assessed blindly by a cardiologist who performed an interrogation and physica examination, an electrocardiogram, an echocardiogram and a 24 hour Holter study. Besides, a rheumatologist performed a clinical and analytical assessment including a qualitative analysis by immunoblotting of anti-Ro Ab and a quantification by chemiluminescence of the anti-Ro52 and Ro60 Ab. The presence of othe SLE specific Ab (ANA, DNA, antiphospholipids), was also analysed. Clinical, analytical and, activity and damage indexes, were collected (SLEDAI and SLICC) The data were compared by Student's t test, Fisher's test and Chi square using 21 SPSS version. The level of significance was established at $5 \%$

Results: 145 patients were included: $91.7 \%$ women, average age $45 \pm 12$, average disease duration 11 years. The patients were undergoing the following treat ments: antimalarial $91 \%$, mycophenolate $20 \%$, azathioprine $12 \%$, biological treatment $5 \%$ and glucocorticoids $70 \%$. The clinical characteristics are summarised in table 1.

There were no significant differences between the group of positive and negative anti-Ro Ab in terms of gender, age, clinical characteristics or cardiovascular risk factors. None of the patients was affected by an atrio-ventricular block and the rest of the electrocardiographic alterations had no clinical significance and did not predominate in the positive Ro Ab group. Additionally, no differences in heart rate, ventricular extrasystoles or PR, QT or QRS intervals were detected between both groups. The echocardiogram's findings were not relevant and there were no differences between groups. 